\title{
Specific detection of foot-and-mouth disease serotype Asia 1 virus by carboxyl-magnetic beads conjugated with single-domain antibody
}

Shunli Yang, Shuanghui Yin ${ }^{*}$, Youjun Shang, Di Wang, Weimin Ma, Jijun He, Jianhong Guo, Jianping Cai and Xiangtao Liu

\begin{abstract}
Background: Immunomagnetic nanobead (IMNB) labeled with specific antibody, has been demonstrated to be useful for the capturing and detection of viruses.

Results: In this study, we developed an imunomagnetic bead based on carboxyl-magnetic beads (MNB) labeled with a single-domain antibody (sdAb) for capturing foot-and-mouth disease (FMD) Asia 1 virus. After magnetic separation, complexes of MNB-sdAb-virus were detected with either a sandwich ELISA or QDs-C5 probe under a fluorescence microscope, and the complexes were used as templates for extraction of total RNA for amplification of the VP1 or 3D gene fragments using RT-PCR and real-time RT-PCR. The Asia 1 VLPs were efficiently captured through IMNB with a high binding rate of $5.09 \mu \mathrm{g}$ of antigen $/ \mu$ of bead suspension. Moreover, this method has been successfully used to capture Asia 1 antigen in synthetic samples.

Conclusion: Ultimately, a specific and highly sensitive capture FMDV Asia 1 tool has been established that has the potential to enhance the sensitivity and reliability when diagnosing FMDV Asia 1.
\end{abstract}

\section{Background}

Foot-and-mouth disease (FMD) is one of most contagious diseases of cloven-hoofed animals including cattle, pigs, sheep, buffalo, and approximately 70 wildlife species. The disease has been identified worldwide where livestock are raised. In the last 20 years, there have been massive outbreaks of FMD in countries formerly free of the disease, such as in Taiwan in 1997 [1], and in the United Kingdom in 2001 [2]. Every outbreak of disease causes enormous economic loss and significant increases in public awareness. The causative agent is FMD virus (FMDV), which consists of a single stranded positivesense RNA genome, encoding a viral polyprotein, and is a member of the genus Aphthovirus within the family Picornavirvidae. FMDV exists in seven different serologically distinct, serotypes: $\mathrm{O}, \mathrm{A}, \mathrm{C}$, southern African Territories 1, 2 and 3 (SAT1-3), and Asia 1. Asia 1 virus initially occurred in 1954 in Okara, Punjab, Paskistan in

\footnotetext{
*Correspondence: yinshuanghui@caas.cn; liuxiangtao@caas.cn State Key Laboratory of Veterinary Etiological Biology, National Foot and Mouth Diseases Reference Laboratory, Lanzhou Veterinary Research Institute, Chinese Academy of Agricultural Sciences, Lanzhou, Gansu 730046, China
}

Asia [3, 4]. FMD Asia 1 virus is its own unique serotype, and outbreaks due to Asia 1 have been reported sporadically in the past few decades. Analyses of Asia 1 indicate that some strains have been spread across large distances between countries in Asia within a short time [5-7].

Conventional technologies, such as the virus neutralization test (VNT) [8], antigen enzyme linked immunosorbent assays (ELISAs) [9-11] and reverse transcription polymerase chain reaction (RT-PCR) $[12,13]$ have markedly improved the detection of FMDV antigen. However, there still exists a general need for sensitive, reliable, and fast specific viral pathogen diagnosis, isolation and identification of the different serotypes of the viruses involved in FMD outbreaks. This is crucial to the prevention and control the spread of FMD, and for minimizing the serious economic consequences that arise from an outbreak at the beginning of the pandemic. In our previous work, we screened and defined a panel of single-domain antibodies (sdAbs) against FMD Asia 1 virus, and constructed the specific probe based on conjugation of sdAb with CdSe/ZnS Quantum Dots (QDs) which were used to trace and image the subcellular 
location of Asia 1 virus in BHK-21 cells [14]. Herein, we extend the application of sdAb in FMDV diagnostic research. Specific Asia 1 virus sdAbs were conjugated onto the surface of carboxyl superparamagnetic beads (MNB) to form immunomagnetic beads (IMNBs) to enable them to effectively capture Asia 1 virus, forming the complexes of beads-sdAb-virus which were easy to specifically and rapidly detect using ELISA and RTPCR. The bead- sdAb-virus complex was also labeled with QDs to measure the stable fluorescence when binding the target virus. These advantages make this a novel assay that can be used for the timely detection of FMD Asia 1 virus with high sensitivity.

\section{Results and discussion}

A critical step is rapid and accurate detection, identification, and isolation of a target pathogen from clinical samples when there is an outbreak of disease. Magnetic beads are a powerful tool with unique advantages, such as controlled surfaces, flexible functionalization, convenience to be manipulated due to their magnetic property, and large surface-to-volume ratios where they can be widely applied to the development of analysis methods. Superparamagnetic beads conjugated with antigens and antibodies are commonly utilized in immunoassays for the enhancement of pathogen detection and separation due to their efficient enrichment and separation capability [15-18].

In this study, we developed a convenient MNB assay based on a sdAb used to specifically capture, recognize, and enrich detection of FMD Asia 1 virus (Fig. 1). To confirm successful conjugation of sdAb onto the surface of the functionalized MNBs capable of binding FMD
Asia 1 virus, the polyclonal serum against Asia 1 antigen can be used form a sandwich ELISA with sdAb coated on the surface of MNBs in the presence of Asia 1 antigen, with the appearance of a HRP signal to indicate the successful conjugation of sdAb with MNB forming the functionalized IMNBs. The reliability and specificity of the method were further carried out by RT-PCR. This demonstrated that the complexes of virus homogeneously mixed with MNBs as all had corresponding VP1 gene fragments, which suggests that the influence of MNBs was insignificant on the extraction of total viral RNA, and was amplified template in RT-PCR reaction. The size of the 460 bp VP1 fragment of Asia 1 virus was observed in the positive samples, while the amount of PCR products of complexes of beads-virus was higher than only the culture samples. The tested samples included FMDV serotype Asia 1, A, O and were synthetic samples detected by RT-PCR after IMNB capture. Results were shown in Table 1 . The IMNB has the ability to specifically bind FMDV Asia 1, moreover the type A and $\mathrm{O}$ samples were all negative in this study. The results suggests that IMNB may bind specifically to FMDV Asia 1, and well enhance sensitivity when diagnosing FMDV Asia 1 using RT-PCR.

The conventional RT-PCR and real-time RT-PCR have been widely used to specifically detect FMDV $[19,20]$. The purpose of this assay was to estimate the binding target virus efficiency of MNBs by real-time RT-PCR and conventional RT-PCR. In the first real-time RT-PCR assay, amplification of the 3D fragment, the TaqMan ${ }^{\circ}$ amplification plot started in the $14.5^{\text {th }}$ cycle (Fig. 2a) which was as template with complexes of beads-virus,

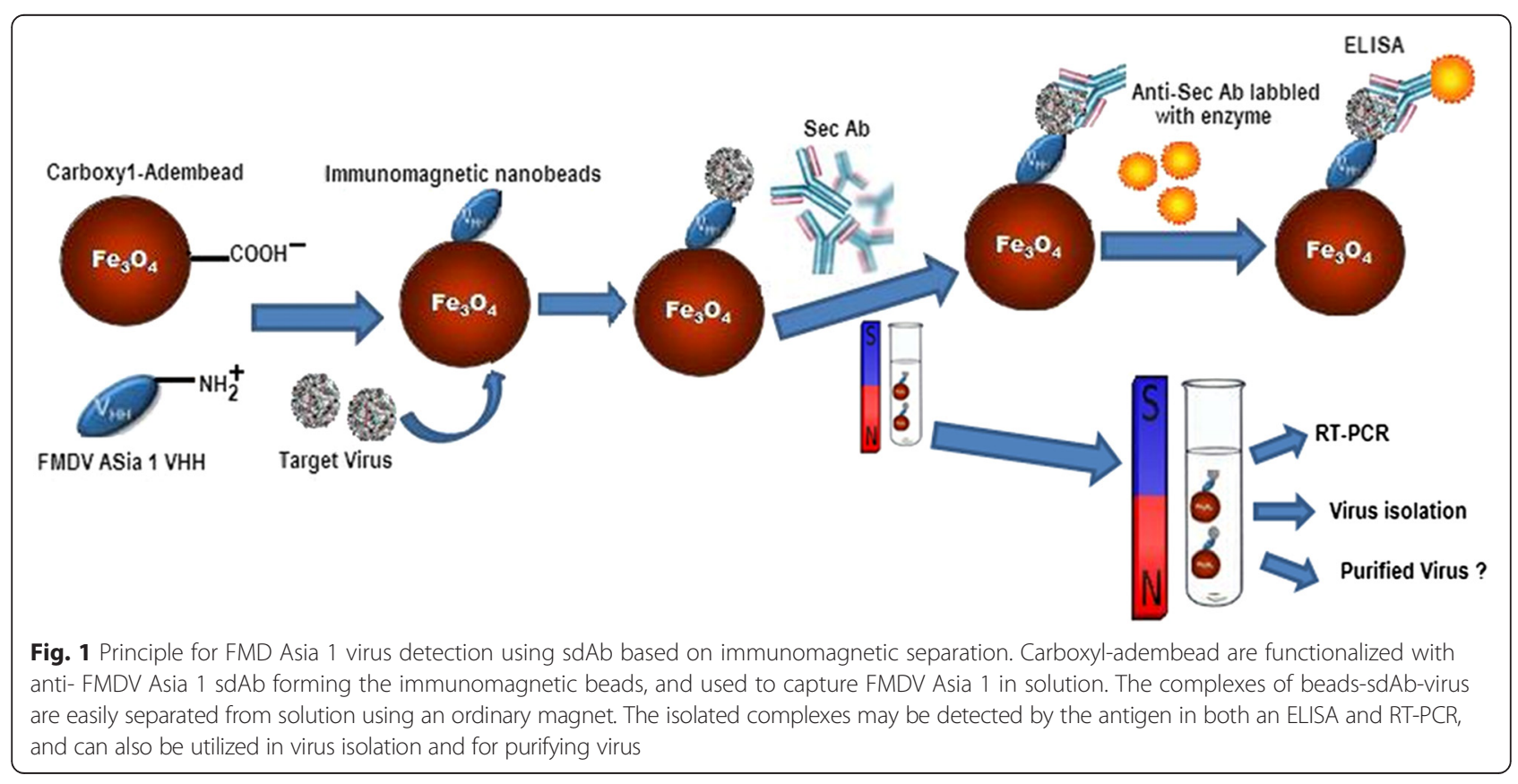


Table 1 Detection of the FMDV samples using IMNB

\begin{tabular}{lll}
\hline Background of Samples & FMDV Serotypes & Asia 1 Results \\
\hline YNBS/58 & Asia 1 & $\mathrm{P}^{*}$ \\
HNK/CHA/05 & Asia 1 & $\mathrm{P}$ \\
HeB/China/1/2005 & Asia 1 & $\mathrm{P}$ \\
HN/2006 & Asia 1 & $\mathrm{P}$ \\
A/GS/LX/62 & Asia 1 & $\mathrm{P}$ \\
synthetic sample 1 & Asia 1/O & $\mathrm{P}$ \\
synthetic sample 2 & Asia 1/A & $\mathrm{P}$ \\
synthetic sample 3 & A/O & $\mathrm{N}^{*}$ \\
\hline
\end{tabular}

$\mathrm{P}^{*}$ and $\mathrm{N}^{*}$ represent Asia 1 positive and Negative, respectively

and comparison of the original virus as template with the amplification plot appeared in the $22^{\text {nd }}$ cycle (Fig. 2b) in the second real-time RT-PCR assay. The parallel conventional RT-PCR tests were performed to amplify the VP1 gene with the same samples. The results demonstrated that the reaction of viruses mixed with the IMNB all received VP1 fragments (460 bp) (Fig. 2c), which suggested the brightness of DNA strips of complexes were more than the original virus (Fig. 2d). However, it is envisioned that the method of capture of FMD Asia 1 virus with IMNB will be used in conjunction with realtime or conventional RT-PCR methods to increase the concentration of target antigen in samples per unit volume in diagnostic process and enhance the sensitivity and reliability for FMDV diagnosis.

To determine the sensitivity of IMNB, it was directly conjugated with the labeled horseradish peroxidase (HRP) sdAb-C6 (HRP-C6. The HRP-C6 was used as a second antibody to monitor the absorbance values in the sandwich ELISA. The absorbance values $\left(\mathrm{OD}_{450}\right)$ reached a stable plateau after $35 \mathrm{~min}$ incubation with different concentrations of viruses from $10^{-1}$ to $10^{-6} \mathrm{TCID}_{50} / \mathrm{mL}$, and the absorbance values for the negative control remained unchanged (Additional file 1: Figure S1).

Some situations that may lead to the nonspecific adsorption of IMNBs when it alone was used to detect the target virus in mixtures, include natural phenomena such as hydrophobic and electrostatic interactions in this polydispersity synthetic system. In response to this, the $\mathrm{pH}$ and salt concentration of the reaction buffer were optimized to reduce the nonspecific background of MNBs, and to enhance the sensitivity. We also found that the largest sample to positive $(\mathrm{S} / \mathrm{P})$ ratio was obtained in $\mathrm{PBS}$ (0.1 mol/L, pH 7.4).

We found the ability to capture antigen of IMNB could be further reconfirmed by calculating the change of concentration of FMD Asia 1 virus VLP antigens after incubation. The P1-2A precursor is processed by viral protease $3 \mathrm{C}$ to produce the structural proteins VP0, VP1, and VP3 which then self-assemble to form icosahedral, empty capsid particles. [21]. The recombinant FMDV VLP contains three structural proteins, VP0, VP1 and VP3 in vivo when observed by SDS-PAGE [22]. We calculated that $1.0 \mu \mathrm{g}$ of MNB (approximately $1.2 \times 10^{8}$ beads) are able to bind $5.09 \mu \mathrm{g}$ target antigen. Additionally, our capture efficiency assay demonstrated that the antigen complex could be dissociated by boiling, and FMD VLPs were lysed into VP0 and $(\sim 32 \mathrm{kDa})$ and VP1/VP3 $(\sim 24 \mathrm{kDa})$ (Additional file 2: Figure S2).
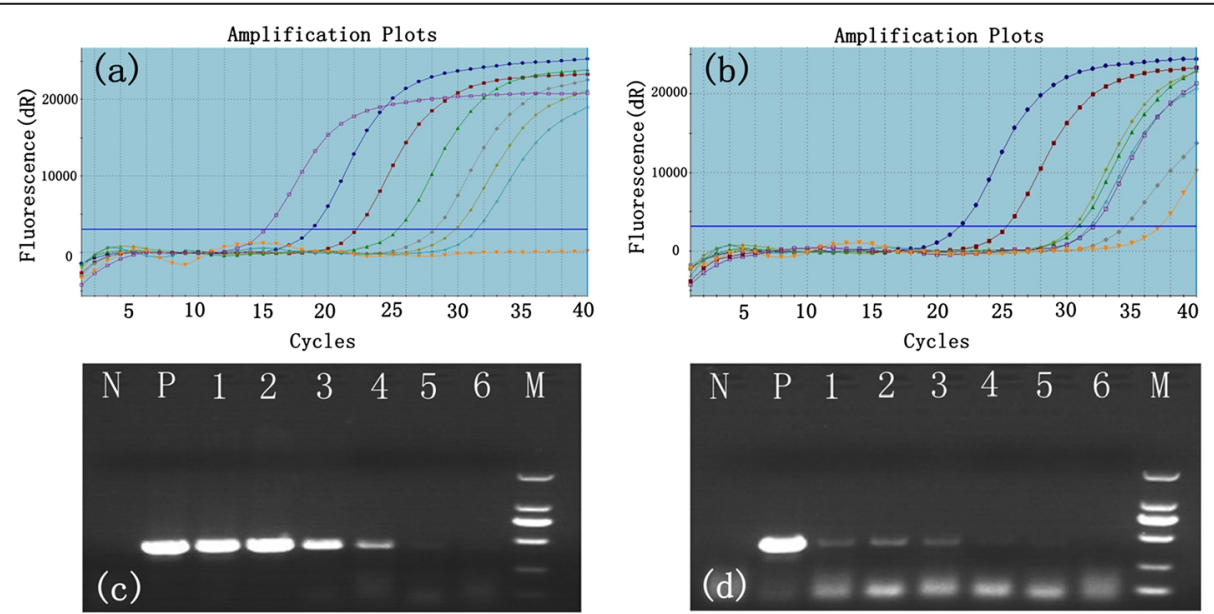

Fig. 2 Serial dilution of primary FMD Asia 1 virus RNA in vitro was amplified to 3D fragment using real-time PCR and general RT-PCR amplifying VP1 fragment based on immunomagnetic to conjugate with sdAb. a FMD Asia 1 virus mixed with IMNBs at the concentration of $10^{-1}$ to $10^{-6} \mathrm{TCID}_{50} / \mathrm{mL}$; b FMD Asia 1 virus was diluted at the concentration of $10^{-1}$ to $10^{-6} \mathrm{TCID}_{5} / \mathrm{mL}$ (c) lane $\mathrm{N}$, negative control using sterile PBS as template; lane P, positive control of primary FMD Asia 1 virus $\left(10^{0} \mathrm{TCID}_{5} / \mathrm{mL}\right)$ reacted with $\mathrm{MNB}$; lanes 1-6, Asia 1 virus mixed with $\mathrm{MNB}$ at the concentration of $10^{-1}$ to $10^{-6} \mathrm{TCID}_{50} / \mathrm{mL}$, respectively; lane M, DL2000 DNA marker 2000, 1000, 750, 500, 250, 100 bp; (d) lane N, negative control using sterile PBS as template; lane $\mathrm{P}$, positive control of primary FMD Asia 1 virus $\left(10^{0} \mathrm{TCID}_{50} / \mathrm{mL}\right)$; lanes $1-6$, FMD Asia 1 virus at the concentration of $10^{-1}$ to $10^{-6} \mathrm{TCID}_{50} / \mathrm{mL}$, respectively; lane M, DL2000 
The capture of the viruses with the IMNBs was observed by TEM. The blackish spots are the beads, while the protuberant spots (result no shown) are characteristic of virion morphology around the beads, because the FMDV particle is too small, at approximately $25 \sim 30 \mathrm{~nm}$ in diameter [23] compared with the beads at about $200 \mathrm{~nm}$ in diameter, which leads to the virus particles not being obvious in the image. The evidence of binding virus was also suggested by the increase in the hydrated particle size of MNBs from $198 \mathrm{~nm}$ to $640 \mathrm{~nm}$ with dynamic light scatting (ZetasizerNano ZS90) (Fig. 3). Binding of the target virus to the functionalized IMNBs could be easily realized by mixing with QDs-C5 and co-localization analysis of beads, FMD Asia 1 virus and fluorescent QDs resulting in QDs-labeled virions. The functionalization of MNBs with $\mathrm{sdAb}$ incubated with FMD Asia 1 virus, were then reacted with QDs-C5, which produced the QDs-labeled virions. The labeled virions were evaluated by confocal fluorescence microscopy, and an overlap of functionalized MNBs between the bright field and fluorescent image (Fig. 4, green) which indicated that functionalized MNBs had successfully captured FMD Asia 1 virus was generated. The number of molecules sdAb conjugated to each MNB was estimated by the fluorescence intensity of the fluorescein-labeled VHH molecular conjugated to magnetic beads [24] and was calculated about 9001200 protein molecular on a bead. The amount of sdAb molecule per bead showed sufficient binding antigen sites to the coupling of target virus to ensure the capture capacity of IMNBs. The combination of QDs and IMNBs offers researchers a new pathway to both separate and identify targets of interest via the use of a simple magnet, and is particularly advantageous in the detection and quantification of soluble biomarkers during which excess QD-antibody constructs must be removed for further analysis [17].

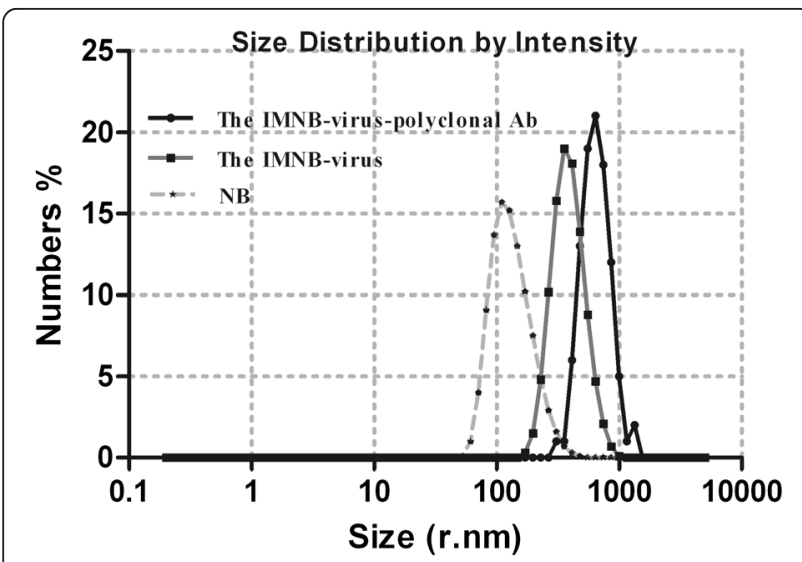

Fig. 3 Characterzaitons of IMNBs by dynamic light scatting. The hydrated particle sizes of beads (198 nm), bead-virus complexes $(356 \mathrm{~nm})$, and the bead-virus-polyclonal Ab complexes (640 nm)
These results suggest that MNBs have a specific capture capacity of FMD Asia 1 virus, while it should be noted that future work towards the translation of this method into the field application must take into account the evaluation of a large volume of actual clinical samples.

\section{Conclusions}

In summary, we have successfully used a specific sdAb conjugated with superparamagnetic beads forming IMNB for the rapid detection of FMD Asia 1 virus. In this method, the IMNB has the ability to efficiently capture the FMD Asia 1 virus to use in a MNB-virus-polyclonal antibody sandwich ELISA, in general RT-PCR and realtime RT-PCR. It was applied to synthetic samples of different serotypes to validate its specificity. Moreover, this method may well enhance the sensitivity and reliability when detecting FMDV Asia 1.

\section{Methods}

FMD Asia 1 virus strain (Genbank: EF149009), sera, BHK21 cell, real-time RT-PCR, general RT-PCR and ELISA kit used in this research were obtained from OIE/CHINA National Foot and Mouth Disease Reference Laboratory, Lanzhou Veterinary Research Institute, CAAS. The sdAbs of clone 5 (C5) and 6 (C6) anti-FMD Asia 1 virus VP1 protein were expressed in E.coli and purified using Ni-NTA agarose [14]. Carboxyl-adembeads super-paramagnetic beads $(200 \mathrm{~nm})$ were purchased from Ademtech SA (Pessac, France), 1-ethyl-3-(3-dimethylaminopropyl) carbodiimide hydrochloride (EDC) was purchased from Sigma-Aldrich (St.louis, MO, USA), QDs (505 nm, green) were obtained from Wuhan Jiayuan Quantum Dots Co.Ltd. (Wuhan, China) which were conjugated with sdAb-C5 to form QDs-sdAb clone 5 (QDs-C5).

\section{Fabrication of immunomagnetic Beads}

According to the product instructions, the carboxyladembeads $(33.33 \mu \mathrm{L} / \mathrm{mg}$ ) were washed 4 times with $0.01 \mathrm{M}$ phosphate buffer solution (PBS, $\mathrm{pH}$ 6.8), then monodispersed in $600 \mu \mathrm{L}$ of $0.01 \mathrm{M}$ PBS. The washed beads were activated in $100 \mathrm{mM}$ EDC and $100 \mathrm{mM}$ NHS in $400 \mu \mathrm{L}$ of $0.01 \mathrm{M}$ PBS for $30 \mathrm{~min}$ at $37^{\circ} \mathrm{C}$ with gentle shaking. Then, they were washed with $0.01 \mathrm{M}$ PBS (pH 7.4) 3 times to remove the excess reagents, and dispersed in $800 \mu \mathrm{L} 0.01 \mathrm{M}$ PBS. The activated beads were mixed with $150 \mu \mathrm{g}$ of sdAb-C6 antibody in $1 \mathrm{~mL}$ $0.01 \mathrm{M}$ PBS at room temperature for $7 \mathrm{~h}$. Afterward, the immunomagnetic bead-C6 (IN-C6) was washed by $0.01 \mathrm{M}$ PBS 5 times, and they were blocked with $1 \mathrm{~mL}$ $3 \%$ BSA for $30 \mathrm{~min}$ at $37{ }^{\circ} \mathrm{C}$. Finally, the functional beads were stored in $0.01 \mathrm{M}$ PBS with $1 \%$ BSA $(\mathrm{m} / \mathrm{v})$ and $0.05 \% \mathrm{NaN}_{3}$ at $4{ }^{\circ} \mathrm{C}$ for use. 

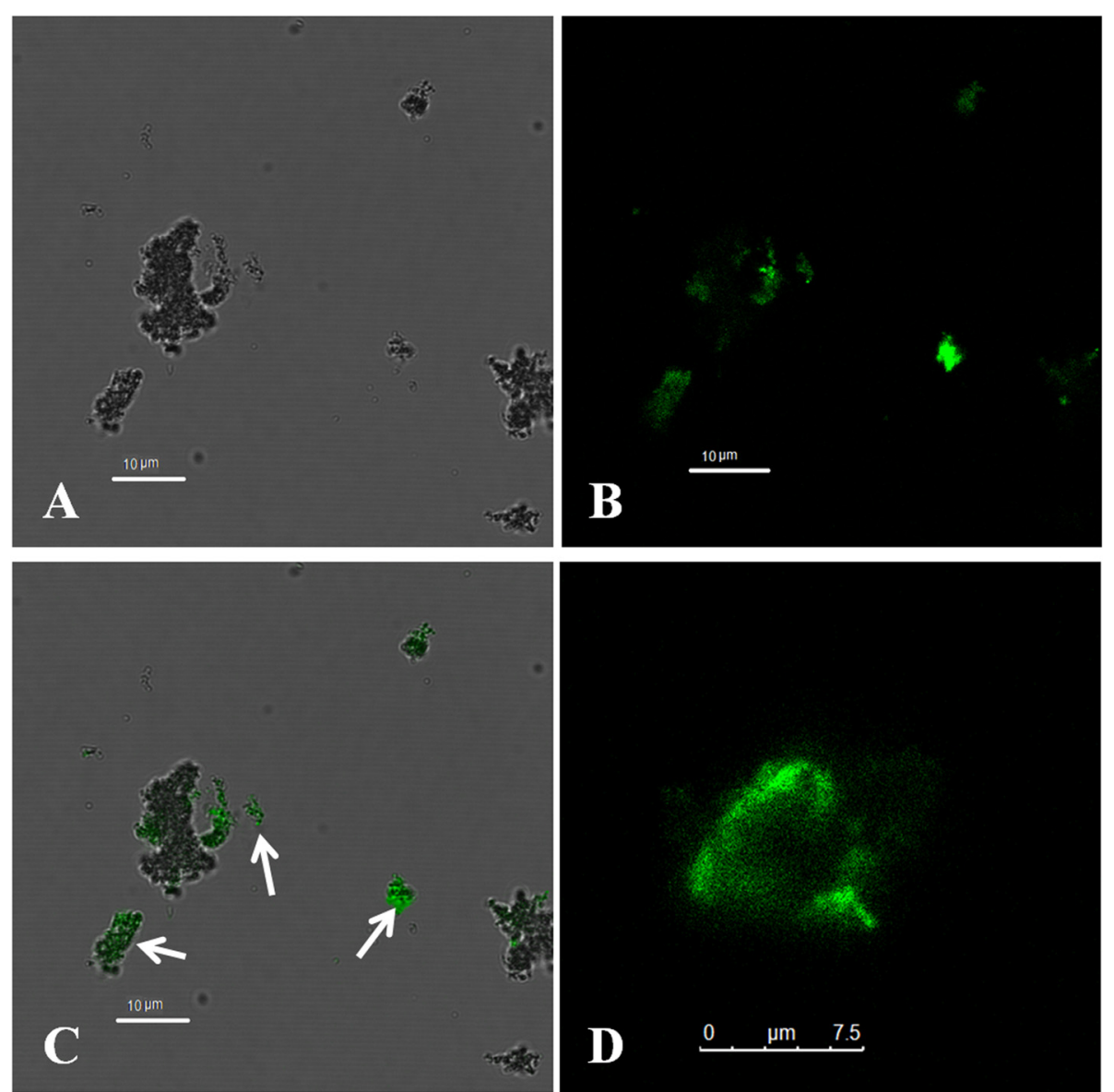

Fig. 4 Confocal microscopic images of fluorescent, MNBs, and complexes of bead-virus. b The fluorescence of QDs-C5 from the labeled target virus (the green spots, on the upper left), a The beads in bright field image (black spots, on the upper right), c The merged image of complexes of beads-virus-(QDs-C5) indicating successful capture of target virus onto the MNB (on the lower left), $\mathbf{d}$ The aggregation of complexes of beads-virus-(QDs-C5) (on the lower right, as indicated by the arrows)

\section{Detection of FMD Asia 1 virus using ELISA and general RT-PCR}

The titer of Asia 1 virus was quantified in BHK-21 cell by $50 \%$ tissue culture infective dose $\left(\mathrm{TCID}_{50}\right)$. Three $\mathrm{mg} / \mathrm{mL}$ (theoretically calculated value was approximately $3 \times 10^{8}$ beads) and $1 \mathrm{~mL}$ inactivated virus samples of $10^{6} \mathrm{TCID}_{50} / \mathrm{mL}$ Asia 1 were simultaneously mixed in $1 \mathrm{~mL}$ of PBS $(0.1 \mathrm{~mol} / \mathrm{mL}, \mathrm{pH} 7.4)$ for a $1 \mathrm{~h}$ incubation at $37{ }^{\circ} \mathrm{C}$ with gentle shaking. The beadvirus complexes were separated by a magnetic scaffold to remove the suspension and washed 3 times using $0.05 \%$ tween-20 in PBS, then resuspended in $300 \mu \mathrm{L}$ PBS. One hundred microliter complexes were detected with a sandwich ELISA. The complexes were added to $100 \mu \mathrm{L}$ anti-Asia 1 guinea pig serum $(1: 1000)$ for $45 \mathrm{~min}$ incubation at $37^{\circ} \mathrm{C}$. After washing 3 times, $100 \mu \mathrm{L}$ of antiguinea pig IgG-HRP at a dilution of 1:100 was added and incubated for $45 \mathrm{~min}$ at $37^{\circ} \mathrm{C}$. After an additional washing step, TMB substrate was mixed with complexes for 10 min at $37^{\circ} \mathrm{C}$, and the reaction was stopped with $2.0 \mathrm{M}$ sulfuric acid. The optical absorbance was measured at $450 \mathrm{~nm}$. Another $200 \mu \mathrm{L}$ of complexes of bead-virus were used as the template to extract the total RNA for the general RT-PCR to amplify the VP1 fragment using the a pair of primers, Vp1F:5'-actaccaccactggcgag-3' and Vp1R:5'gccggttgttcactctgcg- $3^{\prime}$. After optimizing the reacting realtime RT-PCR efficiency using the 10 -fold serially diluted $10^{6} \mathrm{TCID}_{50} / \mathrm{mL}$ culture virus at $10^{\circ}$, and from $10^{-1}$ to $10^{-6}$ in PBS $(0.1 \mathrm{~mol} / \mathrm{mL}, \mathrm{p} \mathrm{H} 7.4), 200 \mu \mathrm{L}$ and $600 \mu \mathrm{L}$ diluent were transferred to new tubes, respectively, the former as a template to extract RNA and detect the $3 \mathrm{D}$ gene which was for the development of a standard curve by real-time RT-PCR, and the latter mixed with MNBs to concentrate target virus according to the process described above. The total RNA was extracted from bead-virus complexes of $600 \mu \mathrm{L}$ sample and virus sample of $200 \mu \mathrm{L}$ which was used as the template in the reaction of the real-time RT-PCR and general RT-PCR, respectively. The negative control was PBS buffer without target RNA in each RT-PCR assay. 


\section{Characterizations of immunomagnetic beads}

The co-localization analysis of bead-virus complexes was performed with interaction with QDs-C5 (505 nm, green). $1 \mathrm{~mL}$ of Asia 1 inactivated virus sample $\left(10^{6}\right.$ TCID $\left.50 / \mathrm{mL}\right)$ was mixed with $20 \mu \mathrm{L}$ of $3 \mathrm{mg} / \mathrm{mL}$ MNBs in PBS (pH 7.4) for $45 \mathrm{~min}$ at $37^{\circ} \mathrm{C}$. After washing by magnetic separation, the complexes were reacted with QDs-C5 for $45 \mathrm{~min}$ at $37{ }^{\circ} \mathrm{C}$ with gentle shaking. After washing, the immune complexes of beads-virus-QDs-C5 were observed by a confocal fluorescence microscope (Leica, TCS SP8). The transmission electron microscopy (TEM) image of beadvirus complexes was observed by a JEM-1230 electron microscope.

All the concentrations of the beads, the hydrated particle size of the NBs, the MNB-virus complexes, and the MNB-virus-polyclonal Ab complexes, were diluted 1:100 (approximately $10^{8}$ beads $\left./ \mathrm{mL}\right)$ in $0.5 \mathrm{~mL}$ of PBS $(0.1 \mathrm{~mol} /$ $\mathrm{mL}, \mathrm{pH}$ 7.4) according to the manufacturer's directions (ZetasizerNano ZS90, Malvern Instruments), and were measured with dynamic light scattering.

\section{Capture efficiency assay}

The recombinant Asia 1 VLPs at a concentration of $2.775 \mathrm{mg} / \mathrm{mL}$ in $200 \mu \mathrm{L}$ of PBS ( $\mathrm{pH} 7.4$ ) were incubated with $50 \mu \mathrm{L}$ of $3 \mathrm{mg} / \mathrm{mL}$ MNBs at $4{ }^{\circ} \mathrm{C}$ for overnight. After removing the supernatant under magnet separation, the beads-virus complexes were washed 3 times with PBS, added to $19 \mu \mathrm{L}$ of PBS and $1 \mu \mathrm{L}$ of $4 \times$ loading buffer, and processed through $12 \%$ SDS-PAGE gel. The capture efficiency was quantified and calculated by measurement of absorbance with a NanoDrop 2000 spectrophotometer ( Thermo, Rockford, IL, USA ).

\section{Detection of the FMDV samples using IMNB}

Tested samples or cell-culture-adapted strains of FMDV Asia 1/YNBS/58 (GenBank: AY390432), Asia 1/HNK/ CHA/05 (GenBank: EF149010), Asia 1/HeB/China/1/ 2005 (GenBank: EF187274), Asia 1/HN/2006 (GenBank: KC412634), O/China/5/99(GenBank:HQ009509), A/GS/ LX/62 (GenBank:AJ131666) and three mixtures (synthetic sample 1: Asia 1/YNBS/58 and O/China/5/99; synthetic sample 2: Asia 1/YNBS/58 and A/GS/LX/62; synthetic sample 3: O/China/5/99 and A/GS/LX/62) were used to mimic real samples, which were provided by OIE/CHINA National Foot and Mouth Disease Reference Laboratory, which were inactivated using binaryethyleneimine to evaluate the diagnostic sensitivity and specificity of IMNB.

\section{Additional files}

Additional file 1: Figure S1. The changes of absorbance values of HRPC6 bound to the complexes of the IMNB-virus with different incubation times by sandwich ELISA. The HRP-C6 was incubated with the complexes of IMNB-virus of $5 \mathrm{~min}, 10 \mathrm{~min}, 15 \mathrm{~min}, 20 \mathrm{~min}, 30 \mathrm{~min}$ and $35 \mathrm{~min}$, respectively. Then the mixtures were washed for four times with PBST, add the TMB substrate was added and incubation at $37^{\circ} \mathrm{C}$ for $30 \mathrm{~min}$. The color reaction was measured at $450 \mathrm{~nm}$. (TIFF $157 \mathrm{~kb}$ )

Additional file 2: Figure S2. Analysis of the capture FMD Asia 1 VLPS products with IMNB by SDS-PAGE. Lane 1: VPO and VP1Np3; M: molecular weight protein ladder. (TIFF $73 \mathrm{~kb}$ )

\section{Competing interest}

The authors declare no conflict of interest relevant to this work.

\section{Authors' contributions}

Conceived and designed the experiments: SLY, YJS, JPC, and XTL. Performed the experiments: SHY, SLY, DW, and JHG. Analyzed the data: SLY, and JJH. Contributed reagents/materials/analysis tools: WMM, and SHY. Wrote the paper: SHY, and XTL. All authors read and approved the final manuscript.

\section{Acknowledgments}

This work was supported by the China Agriculture Research System (CARS-39) and Basic Research Project (no.2013FY113300). We would like to thank assistant researcher Zhenli Gong of the instrument center of our institute for her professional taking photos by confocal fluorescence microscope.

Received: 1 April 2015 Accepted: 31 August 2015

Published online: 15 September 2015

\section{References}

1. Yang P, Chu R, Chung W, Sung H. Epidemiological characteristics and financial costs of the 1997 foot-and-mouth disease epidemic in taiwan. Vet Rec. 1999;145:731-4.

2. Knowles N, Samuel A, Davies P, Kitching R, Donaldson A. Outbreak of foot-and-mouth disease virus serotype $O$ in the uk caused by a pandemic strain. Vet Recc. 2001;148:258-9.

3. Dhanda MR, Gopalakrishnan VR, Dhillon HS. Note on the occurrence of atypical strains of foot-and-mouth disease virus in India. Ind J Vet Sci. 1957;27:79-84

4. Brooksby J, Rogers J. Methods used in typing the virus of foot-and-mouth disease at pirbright, 1950-55. Methods of typing and cultivation of footand-mouth disease virus, European Productivity Agency of the Organisation for European Economic Co-operation, Project. 1957:31-34.

5. Knowles NJ, He J, Shang Y, Wadsworth J, Valdazo-González B, Onosato H, et al. Southeast asian foot-and-mouth disease viruses in eastern asia. Emerg Infect Dis. 2012;18:499.

6. Valarcher J-F, Knowles NJ, Zakharov V, Scherbakov A, Zhang Z, Shang Y-J, et al. Multiple origins of foot-and-mouth disease virus serotype asia 1 outbreaks, 2003-2007. Emerg Infect Dis. 2009;15:1046-51.

7. Ansell D, Samuel A, Carpenter W, Knowles N. Genetic relationships between foot-and-mouth disease type asia 1 viruses. Epidemiol Infect. 1994;112:213-24.

8. Vallat B, Allen G. Manual of diagnostic tests and vaccines for terrestrial animals (mammals, birds and bees). Paris: Office International Des Epizooties; 2004.

9. Morioka K, Fukai K, Yoshida K, Yamazoe R, Onozato H, Ohashi S, et al. Foot-and-mouth disease virus antigen detection enzyme-linked immunosorbent assay using multiserotype-reactive monoclonal antibodies. J Clin Microbiol. 2009;47:3663-8.

10. Ferris NP, Grazioli S, Hutchings $\mathrm{GH}$, Brocchi E. Validation of a recombinant integrin av $\beta 6 /$ monoclonal antibody based antigen elisa for the diagnosis of foot-and-mouth disease. J Virol Methods. 2011;175:253-60.

11. Longjam N, Deb R, Sarmah A, Tayo T, Awachat V, Saxena V. A brief review on diagnosis of foot-and-mouth disease of livestock: Conventional to molecular tools. Vet Med Int. 2011;2011.

12. Bao H-F, Li D, Guo J-H, Lu Z-J, Chen Y-L, Liu Z-X, et al. A highly sensitive and specific multiplex rt-pcr to detect foot-and-mouth disease virus in tissue and food samples. Arch Virol. 2008;153:205-9.

13. El Wahed AA, El-Deeb A, El-Tholoth M, El Kader HA, Ahmed A, Hassan S, et al. A portable reverse transcription recombinase polymerase amplification assay for rapid detection of foot-and-mouth disease virus. PLoS One. 2013;8, e71642.

14. Yin S, Yang S, Shang Y, Sun S, Zhou G, Jin Y, et al. Characterization of asia 1 sdab from camels bactrianus (c. Bactrianus) and conjugation with quantum dots for imaging fmdv in bhk-21 cells. PLoS One. 2013;8, e63500. 
15. Yu X, Xia H-S, Sun Z-D, Lin Y, Wang K, Yu J, et al. On-chip dual detection of cancer biomarkers directly in serum based on self-assembled magnetic bead patterns and quantum dots. Biosens Bioelectron. 2013;41:129-36.

16. Zhao W, Zhang W-P, Zhang Z-L, He R-L, Lin Y, Xie M, et al. Robust and highly sensitive fluorescence approach for point-of-care virus detection based on immunomagnetic separation. Anal Chem. 2012;84:2358-65.

17. Park H, Hwang MP, Lee J-W, Choi J, Lee KH. Harnessing immunomagnetic separation and quantum dot-based quantification capacities for the enumeration of absolute levels of biomarker. Nanotechnology. 2013;24:285103

18. Wen C-Y, Hu J, Zhang Z-L, Tian Z-Q, Ou G-P, Liao Y-L, et al. One-step sensitive detection of salmonella typhimurium by coupling magnetic capture and fluorescence identification with functional nanospheres. Anal Chem. 2013;85:1223-30.

19. Oleksiewicz MB, Donaldson Al, Alexandersen S. Development of a novel real-time rt-pcr assay for quantitation of foot-and-mouth disease virus in diverse porcine tissues. J Virol Methods. 2001:92:23-35.

20. Fosgate G, Tavornpanich S, Hunter D, Pugh R, Sterle J, Schumann K, et al. Diagnostic specificity of a real-time rt-pcr in cattle for foot-and-mouth disease and swine for foot-and-mouth disease and classical swine fever based on non-invasive specimen collection. Vet Microbiol. 2008;132:158-64.

21. Abrams CC, King AM, Belsham GJ. Assembly of foot-and-mouth disease virus empty capsids synthesized by a vaccinia virus expression system. J Gen Virol. 1995;76:3089-98.

22. Cao Y, Sun P, Fu Y, Bai X, Tian F, Liu X, et al. Formation of virus-like particles from o-type foot-and-mouth disease virus in insect cells using codonoptimized synthetic genes. Biotechnol Lett. 2010;32:1223-9.

23. Belsham GJ. Translation and replication of FMDV RNA. Curr Top Microbiol Immunol. 2005;288:43-70.

24. Xie M, Hu J, Long Y-M, Zhang Z-L, Xie H-Y, Pang D-W. Lectin-modified trifunctional nanobiosensors for mapping cell surface glycoconjugates. Biosens Bioelectron. 2009;24:1311.

\section{Submit your next manuscript to BioMed Central and take full advantage of:}

- Convenient online submission

- Thorough peer review

- No space constraints or color figure charges

- Immediate publication on acceptance

- Inclusion in PubMed, CAS, Scopus and Google Scholar

- Research which is freely available for redistribution 